\title{
Bereavement support standards and bereavement care pathway for quality palliative care
}

\author{
PETER HUDSON, R.N., PH.D., ${ }^{1,2,3}$ CHRIS HALL, M.A., B.ED., ${ }^{4}$ ALISON BOUGHEY, в.P.T., ${ }^{5}$ AND \\ AUDREY ROULSTON, PH.D. ${ }^{6}$ \\ ${ }^{1}$ Centre for Palliative Care, St. Vincent's Hospital, Melbourne, Australia \\ ${ }^{2}$ Queen's University, Belfast, Northern Ireland, United Kingdom \\ ${ }^{3}$ University of Melbourne, Melbourne, Victoria, Australia \\ ${ }^{4}$ Australian Centre for Grief and Bereavement, Melbourne, Victoria, Australia; Association for Death Education and \\ Counseling, Victoria, Australia \\ ${ }^{5}$ Positive Women Victoria, Melbourne, Victoria, Australia \\ ${ }^{6}$ School of Sociology, Social Policy, and Social Work, Queen's University Belfast, Northern Ireland, United Kingdom
}

(ReCeIved August 22, 2016; AcCEPTEd May 15, 2017)

\begin{abstract}
Objective: Provision of bereavement support is an essential component of palliative care service delivery. While bereavement support is integral to palliative care, it is typically insufficiently resourced, under-researched, and not systematically applied. Our aim was to develop bereavement standards to assist palliative care services to provide targeted support to family caregivers.

Method: We employed a multiple-methods design for our study, which included: (1) a literature review, (2) a survey of palliative care service providers in Australia, (3) interviews with national (Australian) and international experts, (4) key stakeholder workshops, and (5) a modified Delphitype survey.

Results: A total of 10 standards were developed along with a pragmatic care pathway to assist palliative care services with implementation of the standards.

Significance of results: The bereavement standards and care pathway constitute a key initiative in the evolution of bereavement support provided by palliative care services. Future endeavors should refine and examine the impact of these standards. Additional research is required to enhance systematic approaches to quality bereavement care.
\end{abstract}

KEYWORDS: Bereavement, Palliative care, Family caregivers, Standards, Guidelines

\section{INTRODUCTION}

Provision of bereavement support is an essential component of palliative care service delivery, which is explicitly acknowledged in several seminal national and international publications (National Institute for Clinical Excellence, 2004; World Health Organization, 2004; National Consensus Project for Quality Palliative Care, 2009; De Lima et al., 2012). While bereavement support is integral to palliative care, it is typically insufficiently resourced, under-researched, and not systematically applied (Hudson, 2013; Lynes

Address correspondence and reprint requests to: Peter Hudson, Centre for Palliative Care, St. Vincent's Hospital, P.O. Box 2900, Melbourne, Australia. E-mail: phudson@unimelb.edu.au. et al., 2014; Guldin et al., 2015; Stroebe \& Boerner, 2015; Waller et al., 2016). It may therefore be considered "the forgotten child" of the palliative care family.

Traditional views of bereavement are being challenged in contemporary thanatology (Neimeyer, 2014). Grief following bereavement is not a psychiatric disorder but a normal emotional reaction to loss (Stroebe \& Boerner, 2015). However, while loss and grief are fundamental to human life, the course and consequences of bereavement will vary for each individual. For highly resilient individuals, acute grief may be limited to a few weeks, and for most people their grief subsides over time (Bonanno \& Kaltman, 2001).

For a subgroup of individuals, around $10-15 \%$, the symptoms of distress following the death of a 
family member or friend are more intense and persistent (Prigerson et al., 1996, 2009; Latham \& Prigerson, 2004). Known variously as "complicated grief" (Prigerson et al., 1996; Shear et al., 2011) or "prolonged grief disorder" (Boelen \& Prigerson, 2007), this condition can be associated with severe mental and physical health problems such as insomnia, substance misuse, depression, depressed immune function, hypertension, cardiac problems, cancer, suicide, and work and social impairment. Bereaved individuals in this cohort report higher utilization of medical services and more frequent hospitalizations than people with similar losses whose grief is less intense and of shorter duration. These effects have been observed to last for as long as 4-9 years after the death (Neimeyer \& Burke, 2012). In a summary of the clinical literature on pre-loss risk factors for the development of complicated grief, Neimeyer \& Burke (2012) identified a range of key risk factors, which are outlined in Box 1.

In the palliative care setting, bereaved persons have frequently undertaken caregiving roles that can have both positive and negative features, with caregivers prone to physical and psychological morbidity, financial disadvantage, and social isolation (Hudson et al., 2011). Depression rates between 12 and 59\% (Hudson et al., 2011) and anxiety rates between 30 and 50\% have been reported (Grunfeld et al., 2004; Hudson et al., 2011). Alarmingly, almost half of family caregivers $(n=300)$ in one study (Hudson et al., 2013) met the criteria for psychological distress when measured at the commencement of palliative care provision.

For all bereaved individuals, grief is experienced in the context of their "whole being," including their physical, emotional, cognitive, behavioral, and spiritual manifestations. When grief is complicated and prolonged, evidence suggests that intervention is both indicated and effective (Currier et al., 2008). However, providing universal bereavement services is unnecessary, and offering therapy to resilient individuals is known to be of limited utility (Schut \& Stroebe, 2005; Wittouck et al., 2011).

Therefore, targeting scarce resources for people who will benefit most is important. A tiered or layered approach to bereavement care has been advocated based on metaanalyses of clinical trials (Schut \& Stroebe, 2005). However, there appears to be a dearth of contemporary practice standards that explicitly articulate what resources palliative care services should allocate, when they should allocate them, how, and by whom. Findings from the United States and Australia indicate that bereavement coordinators and counselors are not available in the majority of hospice or palliative care services, bereavement support is highly variable, and there is insufficient evidence-based
Box 1. Key risk factors for complicated grief

Background factors

Close kinship to the dying person (especially loss of spouse or child).

Female gender (especially mothers).

Minority ethnic status.

- Insecure attachment style.

- High pre-loss marital dependence.

- Religion and spiritual beliefs and practices (for some, religious/spiritual belief results in lower levels of grief, and for others a stronger faith can lead to more severe experiences of grief).

Treatment-related factors

Aggressive medical intervention (e.g., intensive care, ventilation, resuscitation).

Ambivalence regarding treatment.

- Family conflict regarding treatment.

- Economic hardship created by treatment.

- Caregiver burden.

Death-related factors

Bereavement overload (multiple losses in quick succession).

- Low acceptance of impending death.

- Violent death (suicide, homicide, accident).

- Finding or viewing the loved one's body after a violent death.

- Death in the hospital (rather than at home).

- Dissatisfaction with death notification.

guidance (Demmer, 2003; Mather et al., 2008). Another study highlighted that less than $5 \%$ of the palliative care budget is directed toward bereavement services (Breen \& O'Connor, 2007). Recent data from Europe also indicate a lack of guidance on bereavement support and a reliance on intuition over evidence when responding to bereavement care needs in palliative care (Guldin et al., 2015). Alarmingly, almost a fifth of palliative care services provide no bereavement support (Guldin et al., 2015). 
Furthermore, services may not formally recognize family caregivers as "clients," so that bereavement support needs for many may go unmet.

Given this background, we developed bereavement support standards to assist palliative care services to provide targeted support to family caregivers. The bereavement support standards were developed for use in all Victorian (Australia) adult specialist palliative care services, including community, inpatient, acute, and consultancy services. They were also designed for potential application to international palliative care services.

\section{DEVELOPMENT PROCESS}

These standards were developed using five phases of data collection. Approval was obtained from the institution's ethical review board. A summary of the data collection methods and main results relevant to informing the content of the standards is provided below. A comprehensive project report is also accessible by visiting www.centreforpallcare.org.

\section{Phase 1}

This phase involved a scoping review of international evidence based on systematic reviews, seminal reports, and guidelines (e.g., Australian Centre for Grief and Bereavement, 2001; Northern Ireland Health \& Social Care Services, 2009; National Institute for Health and Clinical Excellence, 2011; Hudson et al., 2012; Bereavement Services Association and Cruse Bereavement Care, 2013; Waller et al., 2016) conducted over the previous 10 years. As part of this process, the PubMed databases were utilized to search for systematic reviews and guidelines related to bereavement care. The research team reviewed titles and abstracts for those deemed relevant to the palliative care setting. Key reports referenced in the aforementioned were then sourced and reviewed by the research team. Those that were considered "seminal" had a robust developmental process.

Some selective salient findings from this review to assist in formulating the content of our standards included:

While it is important to try and identify the group of people who are most likely to develop complicated bereavement and therefore benefit from specialist bereavement interventions, the research regarding the most appropriate responses is not conclusive. There is insufficient empirical evidence to definitely support the validity of one particular tool to screen for risk of poor bereavement outcome prior to the person's death (Sealey et al., 2015).
- Further work is required to explore strategies to promote resilience, which includes factors and mechanisms that impact on an individual's level of protection against adversities. Resilience is not only a result of an individual's personal attributes, but it can be impacted by a variety of community and cultural factors. The key attributes of resilient individuals (Boerner \& Mancini, 2013) are outlined in Box 2.

Box 2. Key attributes of resilient individuals

- Draw upon past experiences of loss survival.

- Connect with their family and community of care.

- Draw upon religious and spiritual beliefs and practices.

- Identify internal and external strengths and resources.

- Reconstruct a world of meaning and personal identity following the loss.

- Draw upon the experience and support of other bereaved people.

- Have higher levels of practical support.

- Hold a belief in a just world and acceptance of death.

- Gain comfort from talking or thinking about the deceased.

- Given the variability in the adaptation to bereavement, it is difficult to make safe predictions in terms of longer-term functioning of bereaved individuals before a minimum of 6 months post-death. At this point, tools such as the PG-13 (Prigerson et al., 2008; 1995) have been found to have effective predictive validity and reliability for identifying a prolonged and complicated grief disorder.

- Pre-bereavement levels of psychological distress are predictive of post-bereavement maladjustment (Stroebe \& Boerner, 2015), and preexisting conditions seem to be most important in explaining the occurrence of complicated grief (Bruinsma et al., 2015).

- In relation to actually predicting which family caregivers will meet the criteria for prolonged grief disorder (PGD) (as opposed to those reporting high levels of PGD symptoms) at 13 months post-death, the pre-death PGD symptoms appear to be a strong predictor (Thomas et al., 2014). 
- Further research into the components and meanings of "anticipatory grief" and how these may affect bereavement adaptation is required (Stroebe \& Boerner, 2015):

- More sophisticated methods to screen and then target interventions are required, along with exploring patterns of resilience versus risk (Stroebe \& Boerner, 2015).

- Therapy is effective in mitigating the suffering of "at-risk" groups suffering traumatic loss (e.g., bereavement following the death of a child or violent death), and is particularly efficacious when it is offered to those persons with clinically significant symptomatology (Kissane et al., 2006).

- A variety of experiential, cognitive-behavioral, and narrative methods are being developed, showing promising results in the treatment of bereavement-related distress (Neimeyer, 2014).

- A systematic review of grief-counseling interventions highlighted that many studies had methodological limitations but recommended that complicated grief therapy (Shear et al., 2005) and family-focused grief therapy (Kissane et al., 2006) show potential as effective interventions that warrant further empirical investigation (Waller et al., 2016). Establishing feasibility and cost effectiveness of these types of interventions is important.

- Meeting the needs of bereaved persons with complicated grief can be seen as a complex and specialized task requiring input from suitably trained staff (Guldin, et al., 2015).

- Provision of bereavement support for culturally and linguistically diverse groups is a priority (Arthur et al., 2011).

\section{Phase 2}

This phase involved a survey of all publicly funded Victorian palliative care services (in patient and home care). The survey was developed by the project team and sought to obtain a descriptive overview of bereavement provision. It was sent to the manager of all Victorian palliative care services (in patient and home care). Questions (mixture of open and closed) focused on overviews of the bereavement services offered, including by whom and to whom. Palliative care services were also asked about the ways in which family caregivers were screened for risk and their key challenges and priorities related to bereavement care. The survey was completed by 46 of 60 palliative care services, a response rate of $77 \%$.
The majority of palliative care services were using some form of formal or informal bereavement risk assessment and were offering some sort of bereavement support to clients, although there was little consistency regarding the assessment tools being used, staff training, and who was offered bereavement support. The cumulative results of this survey also highlighted the variability of resources for the provision of bereavement support within a palliative care context.

\section{Phase 3}

During this phase, a first draft of the standards was prepared by the research team based on phase 1 and 2 and presented to a project advisory group for feedback and refinement. The expert advisory group was selected in partnership with the Department of Health and comprised the following: a Victoria Department of Health palliative care department representative, a bereavement counselor, a consumer representative, and an interstate bereavement academic. Selection of these advisors was sought via the Victoria Department of Health palliative care department. The advisory group highlighted that standards be adapted to concentrate more explicitly on three areas:

1. Strategies for screening and assessment for psychosocial distress and risk of complicated.

2. Clarity and direction around training requirements and the roles of staff and volunteers to be required.

3. Clarity regarding the specific expectations of palliative care bereavement services.

4. Inclusion of a 'care pathway' to accompany the standards to foster uptake and implementation.

\section{Phase 4}

In phase 4 , the next draft of the bereavement standards were presented at two workshops and then refined. The first workshop $(n=22)$ comprised a range of multidisciplinary palliative care and bereavement health professionals, academics, and service managers from rural, regional, and metropolitan palliative care services. A second workshop $(n=17)$ was convened by Palliative Care Victoria (PCV) (the peak body for palliative care) and comprised members of its psychosocial, spiritual, and bereavement special interest groups.

\section{Phase 5}

In this phase, the penultimate version of the standards and bereavement care pathway were circulated to a group of expert Australian $(n=8)$ and international $(n=4)$ bereavement experts (selected by the 
project advisory committee). The purpose of this approach using a modified Delphi technique was to gain consensus about the specific content, applicability, and evidence underpinning the standards. Only one round of review was required, as all participants confirmed the credibility of the standards and agreed that all key information had been included.

\section{THE BEREAVEMENT SUPPORT STANDARDS FOR PALLIATIVE CARE SERVICES}

These standards are recommended as a minimum level of bereavement support to be provided to primary caregivers and bereaved individuals by specialist palliative care services. This section outlines each of the standards, The criteria for meeting the standards are outlined in the final report (Hall et al., 2012). The guiding principles underpinning these standards are conveyed in Box 3.

\section{Box 3. Principles of bereavement support}

Bereavement support is delivered:

- In a targeted way with those who would benefit most from specialist interventions being identified through structured screening and assessment.

- With a focus on identification of the bereaved person's own resources and capacity that will enhance their resilience.

- Over a period from pre-death to several months post-death and beyond when required.

- With a focus on the primary caregiver but extending to other caregivers/family where resources allow.

- In a way which supports palliative care staff through processes such as death reviews, professional development, and professional supervision.

More detail about the factors to consider when implementing the standards at different points in the bereavement trajectory are contained in the bereavement care pathway (see Table 1).

\section{Standard 1: Access}

All primary caregivers of clients cared for by a specialist palliative care service are eligible to access palliative care bereavement services regardless of age, gender, culture, sexual orientation, socioeconomic status, religious beliefs, physical or other disability, or ability to pay.

\section{Standard 2: Coordination of Bereavement Services}

Bereavement programs in palliative care services should provide coordinated services.

\section{Standard 3: Training and Support}

All staff in a palliative care service, including administrative staff, will come into contact with bereaved people and will therefore require training and support in dealing with bereaved individuals. Staff and volunteers who have contact with bereaved individuals are required to achieve appropriate competencies in delivering bereavement support.

\section{Standard 4: Screening and Assessment}

Screening and assessment for the presence of psychosocial and spiritual distress and risk of complicated grief constitute a continuous process undertaken from the time the client enters the palliative care service to many months after the client's death (where pertinent). These assessments are multidisciplinary and interdisciplinary, as clients may disclose different information to different staff at different times.

\section{Pre-Death Screening and Assessment}

Several tools are recommended for screening for psychosocial distress, including the Distress Thermometer (National Comprehensive Cancer Network, 2013) and the General Health Questionnaire (McCabe et al., 1996; Goldberg et al., 1997). The PG-13 (Prigerson et al., 2008; 1995) has been found to have effective predictive validity and reliability for identifying problematic bereavement experiences.

Where pertinent, the screening should be followed up with a comprehensive holistic assessment and/or referral to a suitably qualified professional. However, there is insufficient empirical evidence to support the validity of one particular tool to screen for risk of complicated bereavement prior to a person's death. For this reason, in addition to the use of a tool, a structured assessment should be undertaken through a conversational exploration of risk factors and strength/resilience factors, as outlined earlier.

\section{Post-Death Screening and Assessment}

Due to the variability in the adaptation to bereavement, it is difficult to make safe predictions in terms of longer-term functioning of bereaved individuals 
Table 1. Bereavement support care pathway

\begin{tabular}{|c|c|c|c|}
\hline $\begin{array}{l}\text { Point on grief } \\
\text { trajectory }\end{array}$ & Actions & $\begin{array}{l}\text { Relevant } \\
\text { standards }\end{array}$ & Factors to consider \\
\hline \multirow[t]{8}{*}{$\begin{array}{l}\text { Between intake and } \\
\text { the client's death }\end{array}$} & $\begin{array}{l}\text { As part of a comprehensive biopsychosocial spiritual } \\
\text { assessment, the team undertakes assessment of } \\
\text { caregiver's risk of complicated grief }\end{array}$ & Standard 4 & $\begin{array}{l}\text { Multidisciplinary/interdisciplinary process } \\
\text { Ongoing conversational examination of risk and resilience } \\
\text { factors }\end{array}$ \\
\hline & $\begin{array}{l}\text { If elevated risk of self-harm or current high levels of } \\
\text { psychosocial distress, refer for specialist intervention }\end{array}$ & Standard 5 & $\begin{array}{l}\text { Urgent referral may be required if risk assessed as high } \\
\text { May need to refer to external agency if expertise does not } \\
\text { exist within palliative care service }\end{array}$ \\
\hline & $\begin{array}{l}\text { If the caregiver meets the criteria (based on the } \\
\text { multidisciplinary team assessment) for bereavement risk, } \\
\text { the team identifies the person as potentially vulnerable } \\
\text { and monitors accordingly }\end{array}$ & Standard 5 & $\begin{array}{l}\text { With the person's consent, if risks are identified, an } \\
\text { appropriate staff member is notified to offer support } \\
\text { The identified caregiver/family member is provided with } \\
\text { support that addresses assessed needs }\end{array}$ \\
\hline & Provision of information and psychoeducational materials & Standard 5 & $\begin{array}{l}\text { Psychoeducation should be provided via a variety of means } \\
\text { such as information sessions, books, and DVDs, and } \\
\text { should focus on: } \\
\text { Preparing the primary carer for the typical role of } \\
\text { supporting a relative/friend }\end{array}$ \\
\hline & & & $\begin{array}{l}\text { Outlining the palliative care services and external } \\
\text { services available }\end{array}$ \\
\hline & & & $\begin{array}{l}\text { Assisting the primary caregiver to support their } \\
\text { relative (e.g., symptom management and psychosocial } \\
\text { support) }\end{array}$ \\
\hline & & & $\begin{array}{l}\text { Self-care strategies for the primary caregiver } \\
\text { (including respite services, if pertinent) }\end{array}$ \\
\hline & & & - Information on death and bereavement \\
\hline \multirow[t]{7}{*}{ Imminent death } & Information provision & Standard 5 & $\begin{array}{l}\text { Ensure that the family is aware that death is imminent } \\
\text { (where possible) }\end{array}$ \\
\hline & & & Assess family preparedness for death \\
\hline & & & $\begin{array}{l}\text { Provide practical information, such as signs of imminent } \\
\text { death, how to arrange a funeral, and the role of the funeral } \\
\text { director }\end{array}$ \\
\hline & & & Information about wills and financial matters \\
\hline & Discussions regarding death decisions & Standard 5 & Who do the client and family wish to be present? \\
\hline & & & $\begin{array}{l}\text { Where would the client and family like the death to occur? } \\
\text { Who is to be notified? } \\
\text { Funeral arrangements }\end{array}$ \\
\hline & For those at risk of complicated grief, provision of more & Standard 5 & Assessment of separation distress and traumatic distress \\
\hline
\end{tabular}
comprehensive support 
At death (as soon as practicable following the death)
Assessment of level of trauma family experienced as a result of the death

Information provision

Specialist bereavement interventions

Death review by multidisciplinary team members

If elevated risk of self-harm or current high levels of psychosocial distress, refer for specialist intervention

\section{At 12 weeks after} death
Information provision

Follow-up phone call for all primary carers

Specialist bereavement interventions
Standard 4 Bereavement overload (multiple losses in quick succession, including non-death losses)

The level of trauma caused to the bereaved by the death, which may be influenced by the experience of suddenness, unexpectedness, or trauma

Place of death (e.g., hospital or home)

Who was present at the time of death?

Any difficult aspects of the death for family and caregivers Dissatisfaction with death notification

Incongruity between client/families expressed pre-death wishes and actual death experience

Important to differentiate between the family's and the health professionals' perceptions of the death. as these may differ markedly

Standard 5 Practical information

Typical grief responses and ways of managing these Seeking assistance for distress, including pertinent bereavement and emergency services

The role of the palliative care team and other support services and how to access them

Standard 5 For people with high levels of psychosocial or spiritual distress or manifesting significant symptoms of separation distress and trauma

Standard 5 Each palliative care team member is provided with an opportunity to reflect on the experience of the client's death and its impact on them

Encourage the use of professional supervision and support

Standard 5 Urgent referral to crisis mental health services may be required if risk assessed as high May need to refer to external agency if expertise does not sit within palliative care service

Standard 5 Information may be provided via follow-up contact (telephone/home visit) or by mail Information includes supports available, such as social/ support groups

Standard 5 Explore issues, including insomnia, social support, return to work, contact with their GP, exacerbation of previously existing psychological, or physical conditions. How have things changed for the person over the previous three months?

If symptoms related to bereavement are unremitting, this may be a sign that further assessment or support is required

Standard $5 \quad$ May require referral for specialist bereavement

interventions based on findings of follow-up phone call/ home visit

Consider a range of interventions, including clinical options, counselling, GP referral 
Table 1. Continued

\begin{tabular}{|c|c|c|c|}
\hline $\begin{array}{l}\text { Point on grief } \\
\text { trajectory }\end{array}$ & Actions & $\begin{array}{l}\text { Relevant } \\
\text { standards }\end{array}$ & Factors to consider \\
\hline \multirow[t]{3}{*}{$\begin{array}{l}\text { Around } 6 \text { months after } \\
\text { death }\end{array}$} & $\begin{array}{l}\text { Undertake formal bereavement assessment of those who } \\
\text { have previously been identified as being at high risk for } \\
\text { prolonged or complicated grief }\end{array}$ & Standard 4 & $\begin{array}{l}\text { Symptoms have been present for at least } 6 \text { months after the } \\
\text { client's death } \\
\text { Symptoms include a sense of disbelief regarding the } \\
\text { death, persistent intense longing, yearning and } \\
\text { preoccupation with the deceased, recurrent intrusive } \\
\text { images of the dying person and avoidance of painful } \\
\text { reminders of death (Prigerson et al., 2008) } \\
\text { Individuals identified as being at elevated risk of } \\
\text { developing prolonged or complicated grief are offered } \\
\text { comprehensive bereavement assessment using a } \\
\text { validated tool such as the PG-13 }\end{array}$ \\
\hline & $\begin{array}{l}\text { For those who meet criteria for prolonged grief, refer to } \\
\text { specialist bereavement services }\end{array}$ & Standard 5 & $\begin{array}{l}\text { Referral to an experienced bereavement worker within the } \\
\text { organisation or to an external organisation }\end{array}$ \\
\hline & $\begin{array}{l}\text { For bereaved individuals assessed as having moderate } \\
\text { psychosocial distress or moderate risk of prolonged or } \\
\text { complicated grief, more formal opportunities to review } \\
\text { and reflect on their grief may be required }\end{array}$ & Standard 5 & $\begin{array}{l}\text { May involve referral to support or social groups } \\
\text { Support may be provided by unpaid staff, such as trained } \\
\text { volunteers } \\
\text { The support of family and friends remains important } \\
\text { throughout the grief trajectory }\end{array}$ \\
\hline
\end{tabular}


before a minimum of 6 months post-death. There are several different tools available to screen for risk (Sealey et al., 2015). Such tools as the PG-13 (Prigerson et al., 1995) appear to have predictive validity and reliability for identifying a prolonged and complicated grief disorder.

\section{Standard 5: Bereavement Support Strategies}

The recommended bereavement supports include two types of strategies:

1. Universal strategies that are targeted at all caregivers and bereaved individuals.

2. Specialist bereavement support strategies targeted at those with elevated risk of developing prolonged or complicated grief or with current psychosocial and/or spiritual distress.

The universal strategies include:

1. Screening and risk assessment as detailed in standard 4.

2. Best-practice symptom management of the terminally ill client to reduce the impact of traumatic death on caregivers as well as the clients themselves.

3. Provision of structured information and support at various points along the grief trajectory, including:

at admission to the palliative care service

a wen death is imminent

a immediately following the death

a at regular intervals following the death, such as 3, 6, and around 12 months (and beyond if appropriate).

4. Provision of access to such support strategies as:

- Participation in a bereavement information session and opportunities to review and reflect on the experience of loss.

- Activity-based programs, such as walking, meditation, music, and art groups.

Specialist bereavement support strategies may include bereavement counseling and psychotherapy using evidence-informed specialist interventions for complicated grief, such as:

- cognitive behavioral therapy (CBT) for complicated grief (Boelen et al., 2006)

- focused family grief therapy (Kissane, 2002)
- complicated grief treatment (Shear et al., 2005)

- meaning reconstruction approaches to grief therapy (Neimeyer, 2000)

online support (Wagner, 2009)

bereavement support groups

In general, the more complicated the grief process, the greater the efficacy of specialist bereavement interventions. The empirical evidence underpinning these interventions should be explored comprehensively prior to implementation.

\section{Standard 6: Clinical Handover and Referral to Specialist Services}

Where provision of bereavement support falls outside the skills and competencies of the palliative care staff, referral to external specialist agencies or practitioners is undertaken.

\section{Standard 7: Community Education and Health Promotion}

The importance of promoting community awareness of bereavement issues and acceptance of the bereaved is recognized and acted upon. Information regarding grief and bereavement is available for general practitioners, employers, and other groups.

\section{Standard 8: Privacy, Confidentiality and Consent}

The palliative care bereavement program ensures the privacy and confidentiality of its bereaved clients.

\section{Standard 9: Integration with the Health and Support System}

The bereavement support program is part of a general health and support system working to promote the health and well-being of bereaved individuals and the wider community.

\section{Standard 10: Resource Allocation}

Resources are allocated in a systematic manner that allows the palliative care service's bereavement program to respond to the changing needs of clients and staff.

\section{Bereavement Support Care Pathway}

Table 1 outlines the recommendations for implementation of the standards along the grief trajectory. While all of the standards apply at each point on the grief trajectory, the table highlights where a specific standard applies to different actions along the bereavement support pathway. 


\section{Formal Endorsement and Implementation}

The final version of the standards was formally endorsed by the Victorian Department of Health's Palliative Care Clinical Network, which provides clinical leadership in the implementation of policy directions and program initiatives in Victoria.

A series of training workshops were subsequently conducted throughout Victoria for palliative care service providers. These offered information about the theoretical rationale for the standards, an update on contemporary bereavement research, and an opportunity to apply the standards to clinical examples, and to develop services and an implementation strategy. Pre and post questionnaires (developed by the project team) were administered to the multidisciplinary attendees $(n=21)$. In addition to significant improvements in participants' knowledge of the Bereavement Support Standards, improvements were also observed in their knowledge of the underpinning theoretical and clinical rationale for the standards, and their knowledge of support strategies across three levels of need, and their progress in identifying implementation strategies, a number of other positive outcomes were identified. Participants valued the opportunity to meet together and work methodically through the standards and their implications for practice.

Following an audit of palliative care services conducted by the Victorian State Auditor (Victorian Government, 2015) the Auditor General advocated that these bereavement standards be utilized to screen individuals at risk of complicated grief and provide appropriate bereavement support. As a result of this, the Department of Health is exploring the use of these standards as performance measures for palliative care agencies.

\section{DISCUSSION}

A key measure of quality palliative care should be the well-being of family caregivers in the years after relinquishing that role (Hudson, 2013). Accordingly, bereavement support should be targeted, evidencebased, and systematically applied. However, the development of bereavement services has lagged behind other palliative care initiatives (Morris \& Block, 2015), and scientific inquiry into meeting the needs of bereaved family caregivers has received insufficient attention (Stroebe \& Boerner, 2015). Given the inconsistency in the delivery of bereavement services by palliative care teams, we set out to develop standards for the provision of bereavement support to be utilized by palliative care services via a multistage process incorporating the best available evidence and expert opinion. The standards were augmented with the development of a bereavement care pathway.

There were several limitations with the standards. They were not specifically targeted for culturally and linguistically diverse populations or for children and other groups with special needs. Caring for the needs of these groups may require enhanced knowledge, skills, and strategies that are not detailed in these standards but are nonetheless critical for provision of best-practice bereavement care. Future attention also needs to be given to how to address the needs of people who have elevated distress but are not part of the small percentage of people who meet the criteria for PGD or have severe complications of grief. While the standards were underpinned by systematic reviews of the literature, a formal evaluation of the levels of evidence was not undertaken. We did explore the impact of training healthcare professionals to implement the standards, but we acknowledge that the sample size was relatively small. We therefore recommend that subsequent research is needed to more comprehensively explore the benefits of training in order to foster successful uptake and implementation.

Given these limitations, we advocate that implementation of the standards should be coupled with a comprehensive evaluation, and we welcome subsequent empirical investigation of the impact of the standards in terms of clinical, resource, and service-delivery outcomes. Direct involvement with bereaved caregivers is essential in the evolution of evidence-based bereavement support. We must dismiss the myth that we need to wait for several months before approaching caregivers for potential research involvement. Data are emerging that family caregivers are willing to be approached sooner rather than later after the death of a relative (Bentley \& O'Connor, 2015), and they can gain rewards from research participation (Hudson, 2004).

The public health model of bereavement support whereby the bereaved are categorized into three risk groups (high, moderate, and low) (Aoun et al., 2015) makes conceptual sense. However, more empirical data are needed to support this approach. The process for determining the scope of a bereavement service has recently been advocated by Morris and Block (2015), and this appears to be a useful guide. It is also vital that future initiatives focus on attempting to minimize the propensity for prolonged grief.

High-quality evidence shows that preparing family caregivers for the role of supporting a person with advanced disease has valuable psychological and social sequelae, including lessening the propensity for distress during bereavement (Hudson et al., 2015). This preparation can comprise such components as: the typical role of being a caregiver, how to support a person with advanced disease, self-care, support 
services, and considerations for impending death and bereavement. These preventative approaches seem to have merit, and more systematic approaches to implementation of such initiatives are warranted.

Developments in bereavement theory are beginning to change our understanding of what constitutes a common response to loss and, by association, our view of what constitutes pathological grief. This shift toward a refined understanding of the heterogeneity of the grief response is particularly important for how we discern who may need more formalized therapeutic intervention (Neimeyer, 2014). Posttraumatic stress disorder, anxiety, and depression, for example, have long been included in the Diagnostic and Statistical Manual of Mental Disorders (see Stroebe \& Boerner, 2015), while persistent complex bereavement disorder is considered a condition for further study. Service providers need to be clear about what they should screen for and what the priority is for formal therapeutic intervention.

\section{CONCLUSIONS}

While the birth of the modern hospice and palliative care movement is about half a century old, unfortunately, the bereavement support scorecard reveals a "fail." Bereavement support is supposedly core to palliative care, yet the rhetoric is not matched by the reality. Bereavement care, with seemingly few exceptions, is haphazard, under-resourced, and lacking a sound evidence base. The standards and care pathway described herewith are an attempt to help enhance the bereavement care agenda. They are not perfect, and we advocate further refinement and testing. Other initiatives, including more research activity (Waller et al., 2016), are beginning to surface, so that with sustained and collective efforts the landscape of bereavement support will show significant signs of improvement.

\section{ACKNOWLEDGMENTS}

This project was funded by the Palliative Care Unit of the Victorian Department of Health under the auspices of the Palliative Care Clinical Network.

Special thanks go to the following:

The personnel who contributed to the development of the standards: Molly Carlile, Pam Harris, Elizabeth Lobb, Chris Pedley, Janine Sayers, Ellen Sheridan, Bill Weidner, Nikola Stepanov, Rachel Zordan, Rachel Allen, and Deborah Clarke.

- Victorian palliative care services' staff who participated in the project survey and interviews.
- Palliative Care Victoria and, in particular, the PCV psychosocial spiritual special interest group and the PCV bereavement special interest group (jointly managed with the La Trobe University Palliative Care Unit).

- International reviewers of the draft final standards, including: Dr. Sherry R. Schachter, Calvary Hospital/Hospice, New York; Dame Barbara Monroe, St. Christopher's Hospice, London; and Prof. Cecilia Chan, University of Hong Kong.

Kylie Fields, for administrative support related to manuscript submission.

\section{REFERENCES}

Aoun, S. M., Breen, L.J., Howting, D.A., et al. (2015). Who needs bereavement support? A population based survey of bereavement risk and support need. PloS One, 10(3), $\mathrm{e} 0121101$.

Arthur, A., Wilson, E., James, M., et al. (2011). Bereavement Care Services: A Synthesis of the Literature. London: Department of Health. Available from https://www. gov.uk/government/publications/bereavement-careservices-a-synthesis-of-the-literature.

Australian Centre for Grief and Bereavement (2001). Minimum Standards for Bereavement Support Programs in Palliative Care Services in Victoria. Melbourne: Australian Centre for Grief and Bereavement.

Bentley, B. \& O'Connor, M. (2015). Conducting research interviews with bereaved family carers: When do we ask? Journal of Palliative Medicine, 18(3), 241-245.

Bereavement Services Association and Cruse Bereavement Care (2013). Bereavement Care Service Standards. Richmond upon Thames: Cruse Bereavement Care. Available from http://www.cruse.org.uk/sites/default/ files/default_images/pdf/Documents-and-fact-sheets/ Bereavement_Care_Service_Standards.pdf.

Boelen, P. \& Prigerson, H. (2007). The influence of symptoms of prolonged grief disorder, depression and anxiety on quality of life among bereaved individuals: A prospective study. European Archives of Psychiatry and Clinical Neuroscience, 257(8), 444-452.

Boelen, P.A., Van Den Hout, M.A. \& Van Den Bout, J. (2006). A cognitive-behavioral conceptualization of complicated grief. Clinical Psychology: Science and Practice, 13(2), 109-128.

Boerner, K. \& Mancini, A.D. (2013). On the nature and prevalence of uncomplicated and complicated patterns of grief. In Complicated Grief: Scientific Foundations for Health Care Professionals. M. Stroebe (ed.), pp. 55-67. London: Routledge.

Bonanno, G.A. \& Kaltman, S. (2001). The varieties of grief experience. Clinical Psychology Review, 21(5), 705-734.

Breen, L.J. \& O'Connor, M. (2007). The fundamental paradox in the grief literature: A critical reflection. Omega, 55(3), 199-218.

Bruinsma, S.M., Tiemeier, H.W., Verkroost-van Heemst, J., et al. (2015). Risk factors for complicated grief in older adults. Journal of Palliative Medicine, 18(5), 438-446. 
Currier, J.M., Neimeyer, R.A. \& Berman, J.S. (2008). The effectiveness of psychotherapeutic interventions for bereaved persons: A comprehensive quantitative review. Psychological Bulletin, 134(5), 648-661.

De Lima, L., Bennett, M.I., Murray, S.A., et al. (2012). International Association for Hospice and Palliative Care (IAHPC) list of essential practices in palliative care. Journal of Pain and Palliative Care Pharmacotherapy, 26(2), 118-122.

Demmer, C. (2003). A national survey of hospice bereavement services. Omega, 47(4), 327-341.

Goldberg, D.P., Gater, R., Sartorius, N., et al. (1997). The validity of two versions of the GHQ in the WHO study of mental illness in general health care. Psychological Medicine, 27(1), 191-197.

Grunfeld, E., Coyle, D., Whelan, T., et al. (2004). Family caregiver burden: Results of a longitudinal study of breast cancer patients and their principal caregivers. Canadian Medical Association Journal, 170(12), 1795-1801.

Guldin, M.-B., Murphy, I., Keegan, O., et al. (2015). Bereavement care provision: A survey by the EAPC Bereavement Care Taskforce. European Journal of Palliative Care, 22(4), 185-189.

Hall, C., Hudson, P. \& Boughey, A. (2012). Bereavement Support Standards for Specialist Palliative Care Services. Melbourne, Victoria: Department of Health. Available from http://dr892t1ezw8d7.cloudfront.net/ wp-content/uploads/2015/12/Bereavement-supportstandards-for-specialist-palliative-care.pdf.

Hudson, P. (2004). Positive aspects and challenges associated with caring for a dying relative at home. International Journal of Palliative Nursing, 10(2), 58-65; discussion 65.

Hudson, P. (2013). improving support for family carers: Key implications for research, policy and practice. Palliative Medicine, 27(7), 581-582.

Hudson, P., Thomas, K., Trauer, T., et al. (2011). Psychological and social profile of family caregivers on commencement of palliative care. Journal of Pain and Symptom Management, 41(3), 522-534.

Hudson, P., Remedios, C., Zordan, R., et al. (2012). Guidelines for the psychosocial and bereavement support of family caregivers of palliative care patients. Journal of Palliative Medicine, 15(6), 696-702.

Hudson, P., Trauer, T., Kelly, B., et al. (2015). Reducing the psychological distress of family caregivers of homebased palliative care patients: Longer-term effects from a randomised controlled trial. Psycho-Oncology, 24(1), 19-24.

Kissane, D. (2002). Family-focused grief therapy: The role of the family in preventive and therapeutic bereavement care. Bereavement Care, 22(1), 6-8.

Kissane, D.W., McKenzie, M., Bloch, S., et al. (2006). Family-focused grief therapy: A randomized, controlled trial in palliative care and bereavement. The American Journal of Psychiatry, 163(7), 1208-1218.

Latham, A.E. \& Prigerson, H.G. (2004). Suicidality and bereavement: Complicated grief as psychiatric disorder presenting greatest risk for suicidality. Suicide \& LifeThreatening Behavior, 34(4), 350-362.

Lynes., C., Phillips., J., Keane, C., et al. (2014). An evaluation of a bereavement program in a US research hospital. The American Journal of Hospice \& Palliative Care, 33(2), 150-153.

Mather, M.A., Good, P.D., Cavenagh, J.D., et al. (2008). Survey of bereavement support provided by Australian palliative care services. The Medical Journal of Australia, 188(4), 228-230.

McCabe, C.J., Thomas, K.J., Brazier, J.E., et al. (1996). Measuring the mental health status of a population: A comparison of the GHQ-12 and the SF-36 (MHI-5). The British Journal of Psychiatry, 169(4), $516-521$.

Morris, S.E. \& Block, S.D. (2015). Adding value to palliative care services: The development of an institutional bereavement program. Journal of Palliative Medicine, 18(11), 915-922.

National Comprehensive Cancer Network (2013). NCCN Clinical Practice Guidelines in Oncology: Distress Management. Fort Washington, PA: National Comprehensive Cancer Network. Available from https://www. nccn.org/professionals/default.aspx.

National Consensus Project for Quality Palliative Care (2009). Clinical Practice Guidelines for Quality Palliative Care, 3rd ed. Pittsburgh, PA: National Consensus Project for Quality Palliative Care. Available from https://www. hpna.org/multimedia/NCP_Clinical_Practice_Guidelines_3rd_Edition.pdf.

National Institute for Clinical Excellence (2004). Guidance on Cancer Services: Improving Supportive and Palliative Care for Adults with Cancer. London: National Institute for Clinical Excellence. Available from https:// www.nice.org.uk/guidance/csg4.

National Institute for Health and Clinical Excellence (2011). Quality Standard for End-of-Life Care for Adults. London: National Institute for Clinical Excellence. Available from https://www.nice.org.uk/guidance/qs13/documents/ qs13-end-of-life-care-for-adults-quality-standard-largeprint-version 2 .

Neimeyer, R.A. (2000). Searching for the meaning of meaning: Grief therapy and the process of reconstruction. Death Studies, 24(6), 541-558.

Neimeyer, R.A. (2014). The changing face of grief: Contemporary directions in theory, research, and practice. Progress in Palliative Care, 22(3), 125-130.

Neimeyer, R.A. \& Burke, L.A. (2012). Complicated grief and the end of life: Risk factors and treatment considerations. In Counseling Clients Near the End-ofLife. J.L. Worth (ed.), pp. 205-224. New York: Springer Science.

Northern Ireland Health \& Social Care Services (2009). The Northern Ireland Bereavement Strategy. Stormont, Belfast, UK: Northern Ireland Department of Health, Social Services, and Public Safety. Available from https://www.health-ni.gov.uk/publications/northernireland-bereavement-strategy-2009.

Prigerson, H.G., Maciejewski, P.K., Reynolds., C.F. III, et al. (1995). The Inventory of Complicated Grief: A scale to measure maladaptive symptoms of loss. Psychiatry Research, 59(1-2), 65-79.

Prigerson, H.G., Bierhals, A.J., Kasl, S.V., et al. (1996). Complicated grief as a disorder distinct from bereavement-related depression and anxiety: A replication study. The American Journal of Psychiatry, 153(11), 1484-1486.

Prigerson, H.G., Vanderwerker, L.C. \& Maciejewski, P.K. (2008). A case for the inclusion of prolonged grief disorder in DSM-V. In Handbook of Bereavement Research and Practice: 21st Century Perspectives. M. Stroebe et al. (eds.), pp. 165-186. Washington, DC: American Psychological Association Press.

Prigerson, H., Horowitz, M., Jacobs, S., et al. (2009). Prolonged grief disorder: Psychometric validation of 
criteria proposed for DSM-V and ICD-11. PLoS Medicine, 6(8), e1000121.

Schut, H. \& Stroebe, M.S. (2005). Interventions to enhance adaptation to bereavement. Journal of Palliative Medicine, 8(Suppl. 1), S140-S147.

Sealey, M., Breen, L.J., O’Connor, M., et al. (2015). A scoping review of bereavement risk assessment measures: Implications for palliative care. Palliative Medicine, 29(7), 577-589.

Shear, K., Frank, E., Houck, P.R., et al. (2005). Treatment of complicated grief: A randomized controlled trial. The Journal of the American Medical Association, 293(21), 2601-2608.

Shear, M.K., Simon, N., Wall, M., et al. (2011). Complicated grief and related bereavement issues for DSM-5. Depression and Anxiety, 28(2), 103-117.

Stroebe, M. \& Boerner, K. (2015). Caregiving and bereavement research: Bridges over the gap. Palliative Medicine, 29(7), 574-576.

Thomas, K., Hudson, P., Trauer, T., et al. (2014). Risk factors for developing prolonged grief during bereavement in family carers of cancer patients in palliative care:
A longitudinal study. Journal of Pain Symptom Management, 47(3), 531-541.

Victorian Government (2015). Victorian Auditor General's Report on Palliative Care. Victoria: Australia. Available from https://ace-notebook.com/view.php?res=1ufV2a WYnerY4JnK49fK3Znf19aP0NrfnNTWmNve0N_KzMz d1-LP3JqbnqSWmZ-ao6CxytfV19TV0uHOm9bC29CYo KOSnpudn6iOuczV2tzC3dTf06DEyt3OnOPFz3ZsNjM $\mathrm{x} \&$ keyword=Palliative+Care+-+VAGO\&a=oqSSnqGbTF wyMQ\&b=00dBKTMx.

Wagner, B. (2009). Internet-based interventions for complicated grief. Grief Matters, 12(2), 44-47.

Waller, A., Turon, H., Mansfield, E., et al. (2016). Assisting the bereaved: A systematic review of the evidence for grief counselling. Palliative Medicine, 30(2), $132-148$.

Wittouck, C., Van Autreve, S., De Jaegere, E., et al. (2011) The prevention and treatment of complicated grief: A meta-analysis. Clinical Psychology Review, 31(1), 69-78.

World Health Organization (2004). Cancer Pain Release. Available from http://www.who.int/cancer/publications/cancer_pain_release/en/. 